REVISTA ANDALUZA DE ANTROPOLOGÍA.

NÚMERO 4: ENCRUCIJADAS PARA LAS SOCIEDADES PESQUERAS DEL SUR EN EL MARCO DE LA GLOBALIZACIÓN. MARZO DE 2013

ISSN 2174-6796

[pp. 55-78]

http://dx.doi.org/10.12795/RAA.2013.i04.04

Fecha de recepción: 18/12/2012

Fecha de aceptación: 12/02/2013

\title{
UNA PROPUESTA PARA EL ANÁLISIS DE LA ARTICULACIÓN SOCIAL DEL LITORAL ANDALUZ A TRAVÉS DE LA PESCA
}

\author{
Rafael Cáceres Feria \\ Ma Ángeles Corbacho Gandullo \\ Universidad Pablo de Olavide \\ Grupo de Investigación Social y Acción Participativa (GISAP)
}

\section{Resumen}

Desde el presente artículo se pretende denunciar una triple invisibilización: de las actividades pesqueras en la historia de Andalucía, de la diversidad y complejidad sociocultural que comportan, y de los flujos de relaciones humanas a que dan lugar. Esta perspectiva resalta la capacidad de la pesca de generar contactos y convivencias, y nos lleva a considerarla como un elemento vertebrador del litoral a lo largo de la historia. Con este fin, hemos elaborado una síntesis de los movimientos poblacionales que ha generado la pesca en Andalucía desde una perspectiva histórica. Asimismo, presentamos el caso de una comunidad de pescadores producto de una de estas migraciones, donde destacamos la especial significación que han tenido para estos marineros las estrategias productivas y reproductivas basadas en las experiencias colectivas en sus lugares de origen $y$, a la vez, el cambio de posición de estos pescadores en la sociedad local de acogida. Finalmente, a modo de epílogo, se plantea una propuesta metodológica para abordar el estudio de la pesca en Andalucía en respuesta a las imágenes historiográficas más extendidas. 
Palabras clave. Pescadores, migraciones, Andalucía litoral, culturas del trabajo, historiografía pesquera, metodología.

\begin{abstract}
This article is to report a triple invisibility: first, that of the fishing activities in the history of Andalusia, secondly that of the diversity and socio-cultural complexity that involves and, finally, that of the flow of human relationships that implies. This perspective highlights the fishing capacity to generate contacts and living together, and leads us to consider this activity as a coast principal support throughout history. For this purpose, we have developed a historical synthesis about population movements generated by the fishing in Andalusia. We also present the study of a fishing community, result from migration of sailors from the East to the West of Andalusia. We analyze the productive and reproductive strategies based on the collective experiences in their hometowns. And, at the same time, the change in the position of these fishermen in the local society. Finally, as an epilogue, we propose a methodology for the study of fisheries in Andalusia in response to images historiographical most widespread.
\end{abstract}

Keywords. Fishermen, migrations, Andalusia, littoral, work cultures, historiography fishing, methodology.

\title{
1. ANDALUCÍA OCCIDENTAL, ANDALUCÍA ORIENTAL, ANDALUCÍA LITORAL
}

Es frecuente a la hora de hablar de Andalucía hacer referencia a dos realidades geográficas distintas, la zona más oriental o Alta Andalucía, dominada por los agrestes paisajes de las Béticas, y la occidental o Baja Andalucía, un área caracterizadas por la amplias llanuras del Valle del Guadalquivir. Para muchos esta diferencia entre una Andalucía Oriental y una Occidental no es exclusivamente geográfica, va más allá, tiene también un trasfondo histórico. La Andalucía Occidental la conforman las tierras que primero fueron conquistadas por las tropas cristianas y que, por lo tanto, antes se castellanizaron. La Oriental corresponde con el territorio del Reino Nazarita que se incorporó a Castilla más de dos siglos después. Estas bases geográficas e históricas son las que se suelen utilizar para defender la existencia de dos Andalucía culturalmente distintas. Una división que habitualmente, explícita o implícitamente, se da por hecho y pocas veces se cuestiona. Así, cuando se quiere explicar las variaciones de cualquier fenómeno en tierras andaluzas esta es la primera variable a la que se acude. Sin negar las evidencias geográficas e históricas, creemos que esta dicotomía no refleja adecuadamente la realidad andaluza. Andalucía con más de $87.597 \mathrm{~km}^{2}$ y un accidentado territorio constituye un espacio mucho más complejo. Basta con observar la diversidad de cualquiera de las provincias andaluzas para comprender que estamos ante una clara simplificación. 
Muy pocas veces cuando se habla de Andalucía se tiene en cuenta un hecho de gran relevancia, la existencia de un enorme litoral que de oeste a este se extiende desde la desembocadura del río Guadiana, rayano con Portugal, hasta Cala Cerrada, en el límite entre Almería y Murcia. Más de ochocientos kilómetros de costas bañadas por las aguas del Atlántico y del Mediterráneo. Se tiene constancia que por estos mares, desde tiempos prehistóricos, se ha producido un constante trasvase de gentes de un lado a otro de Andalucía. Un mar que ha facilitado unas relaciones que las malas comunicaciones terrestres frecuentemente dificultaban. Muchos siglos antes de la apertura de la A-92, la autovía que une el occidente con el oriente vertebrando Andalucía, marineros del Mediterráneo se desplazaban regularmente por mar hasta el Golfo de Cádiz. Los continuos contactos entre las tierras litorales andaluzas explicarían muchas de las similitudes que podemos encontrar entre poblaciones alejadas cientos de kilómetros por tierra ${ }^{1}$. Así, un habitante de Ayamonte probablemente tenga mucho más en común con uno de Torre del Mar, población situada a cerca de 400 kilómetros por tierra, que con uno de Villablanca, localidad onubense del interior, que distan unos escasos 16 kilómetros. No olvidemos que hay unos elementos compartidos por una gran parte de las poblaciones costeras, desde Ayamonte hasta San Juan de los Terreros, y que explican estas grandes similitudes. Nos referimos a la cultura del trabajo generada por la actividad pesquera. $\mathrm{Y}$ es que no ha sido únicamente la presencia del mar lo que ha unido a las localidades costeras andaluzas, sino, sobre todo, la explotación de sus recursos, la pesca. Como veremos, durante siglos, embarcaciones y marineros, no solo andaluces, se han desplazando y siguen desplazándose, en un vaivén constante, de un lado a otro de la costa. Isleños en Conil, carboneros en Ayamonte, sitgetanos en Isla Cristina, portugueses en la Antilla, barbateños en Castellón... Solo así se puede explicar la existencia de una Andalucía costera con una marcada personalidad.

Resulta sorprendente que ni geógrafos, ni historiadores, ni antropólogos se hayan interesado por conocer los movimientos provocados por la actividad pesquera y las grandes consecuencias que han tenido en todos los ámbitos: lenguaje, devociones, alimentación, innovaciones pesqueras, etc. Las investigaciones al respecto son muy escasas, lo que nos lleva a preguntarnos el porqué de este olvido, por qué la falta de interés por esta realidad andaluza. Son muchas las razones que se podrían esgrimir para dar respuestas a estas preguntas pero hay dos cuestiones que son especialmente significativas. Por un lado, el desinterés por el mundo pesquero. Y por otro, la existencia

1. Nos puede servir de ejemplo un rasgo lingüístico, la distribución del seseo y ceceo por la geografía andaluza. No existe al respecto esa dicotomía occidental/oriental. Así, por ejemplo, en una sola provincia, la de Huelva, encontramos que en la sierra, se distingue s y c, en las tierras centrales del Andévalo se sesea y en la costa se cecea. Sin embargo, prácticamente en todo el litoral andaluz, exceptuando las capitales de provincia, se cecea, tanto en la parte occidental como en la oriental. 
de una imagen de una Andalucía rural y/o turística que se ha proyectado de manera dominante.

El interés de los estudios pesqueros por las técnicas extractivas y los aspectos económicos contrasta con la poca atención prestada a la población que se dedica a esta actividad. Muchos trabajos sobre pesca tienden a presentar una imagen de las áreas pesqueras andaluzas en las que los elementos cambiantes son únicamente las embarcaciones o artes de pesca, mientras que los pescadores son un factor invariable, dando por hecho que la población vinculada al sector es siempre de la zona. Con frecuencia se olvida que si bien determinadas especies marinas y modalidades pesqueras pueden estar vinculadas a áreas geográficas concretas, la población marinera se desplaza de un lugar a otro, participando en distintos contextos. Resulta imposible entender el desarrollo pesquero sin estos trasvases de población pues estas migraciones no solo suponen el desplazamiento de la fuerza de trabajo sin más, sino, también, de conocimientos y estrategias económicas vinculadas a la mar.

Salvotrabajosqueabordan migraciones pesquerasespecialmentellamativas, essignificativa la escasez de estudios sobre desplazamientos de pescadores. La falta de investigaciones al respecto contribuye a generar una imagen de la Andalucía litoral especialmente estática y fragmentada. Las costas almeriense, granadina, malagueña, gaditana y onubense parecen mundos distintos sin ninguna conexión entre sí. Si queremos conocer cómo ha sido el desarrollo pesquero de Andalucía es imprescindible tener en cuenta estas migraciones, que nos ayudarán a entender cómo se han producido importantes cambios en el sector ¿Cómo comprender la evolución pesquera de Ayamonte, en las últimas décadas, sin la presencia de pescadores almerienses y malagueños? ¿Cómo explicar el desarrollo de la pesca de cerco en Castellón sin considerar la aportación de los marineros andaluces, sin tener en cuenta su experiencia acumulada? ¿Cómo entender el desenvolvimiento de las almadrabas del Estrecho en la actualidad sin contemplar el trabajo y conocimientos técnicos aportados por los almadraberos procedentes del poniente andaluz?

Cuando se habla de Andalucía como crisol de culturas se suele poner el acento en la mezcla cultural en un pasado más o menos remoto. Sin embargo, el litoral andaluz, ha sido y continúa siendo ese crisol, un territorio de promiscuidad cultural donde convergen gentes venidas de los rincones más diversos: italianos, catalanes, valencianos, portugueses..., dando lugar a un rico patrimonio pesquero que no siempre se ha sabido valorar y preservar (Alegret, 2003; Cáceres, 2007; Corbacho, 2006; Florido, 2003). Los desplazamientos de pescadores más recientes tampoco han tenido un tratamiento específico. La masiva salida de miles de andaluces a Madrid, Cataluña y a numerosos países europeos, en la segunda mitad del XX, ha despertado el interés de historiadores, geógrafos, sociólogos y antropólogos, generando una amplia bibliografía. Curiosamente estos trabajos se centran casi de forma exclusiva en el éxodo rural y casi nunca se especifica 
la salida de marineros. Se entendería que la población pescadora forma parte de esa legión de emigrantes que se emplearon en las fábricas del Norte. Sin embargo, sabemos que paralela a esas migraciones, a mediados de los sesenta, se produce la emigración de marineros de todo el litoral andaluz a los puertos del País Vasco: Lekeitio, Ondarroa, Motriko, Bermeo. Se trata de emigraciones muy condicionadas por la cultura del trabajo. Con el fin de evidenciar las posibilidades que la actividad pesquera posee para generar contactos y convivencias y el papel que ha jugado en la articulación del litoral andaluz, nos proponemos seguidamente dar cuenta, desde una perspectiva histórica, de la especificidad de los movimientos migratorios de la población pescadora andaluza.

\section{MIGRACIONES PESQUERAS EN EL LITORAL ANDALUZ. UNA APROXIMACIÓN HISTÓRICA}

La pesca a lo largo de la costa mediterránea y suratlántica de la Península Ibérica es una actividad milenaria, ligada a los primeros asentamientos humanos. El aprovechamiento de los recursos marítimos ha sido fundamental en la vida de las poblaciones litorales. Sin embargo, al analizar la génesis de las civilizaciones mediterráneas se suele destacar el papel jugado por la agricultura, la minería o el comercio, relegando la pesca a un segundo plano y olvidando que parte de los pueblos costeros poseen una economía y una cultura pesquera. La extracción de recursos marinos y el comercio de salazones de pescado ha sido uno de los motores de los desplazamientos entre el Mediterráneo y el Atlántico desde la Antigüedad.

A riesgo de generar un discurso lineal y simplificador creemos pertinente constatar estos flujos poblacionales vinculados a la actividad pesquera, tratando de romper esa imagen estática de la pesca en Andalucía ${ }^{2}$. Nos limitaremos a visibilizar la movilidad de pescadores a lo largo de la Edad Contemporánea desde una triple direccionalidad: la atracción que ha ejercido la riqueza pesquera del litoral andaluz y que ha provocado la llegada de pescadores de otros puntos de España y de Europa; los desplazamientos de los marineros andaluces desde unos puertos a otros de Andalucía y, finalmente, la salida de trabajadores de la mar desde el litoral andaluz hacia otros puntos de España, Europa y África.

Se suele tomar los inicios de siglo XVIII como punto de inflexión en la evolución de la pesca en Andalucía, tanto por lo que supone la integración del sector pesquero andaluz en un mercado estatal más amplio, como por la introducción de numerosas innovaciones técnicas (artes, embarcaciones, métodos de conservación) que conducirán

2. No pretendemos realizar una síntesis histórica de la pesca en Andalucía. Sin embargo, para cubrir el objetivo de visibilizar los flujos poblacionales asociados a la pesca, hemos de conectarlos, aunque sea someramente, con las transformaciones sufridas en las fases extractiva, industrial y comercial del sector en tanto que conformadoras de la geografía pesquera andaluza en el periodo analizado. 
a una progresiva transformación de esta actividad económica (Compán, 1989:223). Una de las imágenes historiográficas más extendidas es la que vincula este proceso de cambio con la arribada al litoral andaluz de pescadores y fomentadores levantinos -catalanes y valencianos- (cf. Martínez, 1978, 1998; Jou, 1995). Sin embargo, sin negar la importancia que estas migraciones tuvieron, habría que constatar que desde hacía siglos se desarrollaban en Andalucía actividades pesqueras con un claro componente comercial, desde las almadrabas del Estrecho, pasando por la extracción, transformación y comercialización de la sardina, o la pesca de altura en aguas africanas (cf. Rumeu, 1956, 1977; González, 1998). Actividades pesqueras que generaron históricamente importantes trasvases poblacionales ${ }^{3}$. Asimismo, como informa García del Hoyo (2006), la ruta que conectaba con el levante peninsular no era nueva, pues desde finales del siglo XV operaba en manos de comerciantes andaluces la exportación de pescado seco y salado a los puertos levantinos, si bien había experimentado un retroceso en la segunda mitad del XVII debido a los continuos ataques berberiscos. Por tanto, lo que ocurre a partir del siglo XVIII será que estos fomentadores y pescadores catalanes se hacen con el control de este circuito de comercialización.

Uno de los aspectos más destacables de estas migraciones es el surgimiento o la reactivación de enclaves pesqueros en el litoral de Andalucía. Los levantinos tomarán como centro de operaciones la costa atlántica andaluza (Miravent, 1981 [1824]; Gonzálvez, 1988), el Algarve portugués (Athaide, 1908) y el litoral de Málaga (Burgos, 2003). En puntos estratégicos, especialmente en playas y desembocaduras de ríos, fundarán diversas colonias que actuarán como focos de atracción de familias de pescadores procedentes del levante español, de toda la costa andaluza y el sur de Portugal ${ }^{4}$. Una vez aquí, se dedicaban al trabajo en las almadrabas, jábegas y sedales y en las factorías salazoneras. Entre las principales contribuciones de estos fomentadores será el desarrollo de la

3. Desde los puertos más importantes del Golfo de Cádiz -Ayamonte, Lepe, Cartaya, Gibraleón, Huelva, Moguer, Palos, Sanlúcar de Barrada y El Puerto de Santa María- saldrán naves hacia África. La captura de pescada era el principal atractivo de estas pesquerías situadas en aguas marroquíes: Cabo Espartel y Azamor. A finales del XVI esta actividad comenzará a declinar como consecuencia de la inseguridad de la zona (ibid.366). Los andaluces no eran los únicos que se adentraban en aguas africanas. Portugueses, canarios y gentes del Cantábrico también explotaban estas pesquerías. Los puertos andaluces eran utilizados como bases por los pescadores llegados de la costa asturiana y santanderina: San Vicente de la Barquera, Llanes, Rivadesellas, Gijón y Avilés (ibid. 364). Asimismo, marineros andaluces se instalarán en la costa canaria.

4. Con el paso del tiempo, el asentamiento catalán más importante en la costa de Huelva fue La Higuerita, origen de la actual Isla Cristina. 
industria de salazón que, a su vez, provocó la intensificación del esfuerzo pesquero ${ }^{5}$. Las consecuencias de estos cambios se dejaron sentir rápidamente: se produjo una especialización productiva y se aceleró el proceso de proletarización de la población pesquera.

Lo mismo que había sucedido en siglos anteriores este crecimiento pesquero no fue continuo. Las incesantes epidemias, la inestabilidad política del Estado, las guerras marítimas, la competitividad de otros productores, el agotamiento de la pesca y los gravámenes sobre la sal hacen que las compañías catalanas se vayan retirando de aguas andaluzas a fínales del XVIII ${ }^{6}$. No será hasta la segunda mitad del XIX cuando comience a vislumbrase algunos síntomas de recuperación económica, iniciándose una nueva fase de expansión en el contexto de liberalización de las actividades pesqueras ${ }^{7}$. Muchos armadores locales ampliaron sus negocios a la salazón de sardinas, ya en la década de los ochenta comenzará el desarrollo de la industria conservera, primero en Cádiz, de la mano de empresarios italianos, y luego en Huelva. Para abastecer esta industria, en Isla Cristina y Ayamonte surge una flota de embarcaciones sardineras de gran tamaño, los denominados galeones, que utilizaban grandes redes de cerco, las tarrafas, de gran capacidad extractiva. Este proceso de industrialización de la actividad pesquera generará una clara diferenciación entre la costa atlántica, con una mayor producción extractiva, industrial y comercial, y la mediterránea, con predominio de la pesca artesanal (Cáceres, 2002; Ríos, 2005). Nuevamente, estas diferencias originarán importantes movimientos poblacionales de pescadores hacia el Golfo de Cádiz.

La cercanía de la frontera portuguesa y la demanda de mano de obra en embarcaciones, puertos y fábricas propiciaron un fuerte trasvase de portugueses a la costa onubense. En las localidades costeras y en las playas de Isla Canela, Punta del Caimán, Punta del Moral, El Rompido o El Portil se asentaban pescadores lusos durante las temporadas de pesca. Procedían mayoritariamente del litoral del Algarve: Monte Gordo, Tavira, Olhao, Cacela.... (López, 2004). Terminarán mezclándose con las poblaciones autóctonas

5. Los levantinos introdujeron un nuevo procedimiento de salazón, el salprensado o arengado, técnica que posibilitaba aumentar la vida del producto, lo cual posibilitaba la ampliación de los mercados. Exigía mayor cantidad de sal que las salmueras tradicionales, de ahí la idoneidad de situar estas fábricas cerca de emplazamientos salineros.

6. Este hecho no quiere decir que una parte de estos fomentadores catalanes y valencianos no se establezcan en determinadas poblaciones y pasen a formar parte de las elites pesqueras andaluzas.

7. La abolición de los privilegios señoriales en la explotación de las almadrabas y otras pesquerías, la supresión de la Matrícula del Mar, el desestanco de la sal y el levantamiento de las prohibiciones sobre los procedimientos de extracción intensiva, son algunos de los hitos específicos que conforman la liberalización del sector en este periodo. 
aunque algunos núcleos, como el poblado de La Antilla, subsistirán diferenciados hasta nuestros días. La presencia de marineros portugueses no se limitará a la costa de Huelva, en menor número, también se desplazarán a localidades litorales gaditanas.

Por la misma época en que se produce la llegada de portugueses, desde el lado opuesto de Andalucía, desde Almería, se trasladarán hasta los puertos gaditanos y onubense un importante contingente de pescadores buscando trabajo en el sector pesquero. Las almadrabas y los barcos sardineros fueron sus principales ocupaciones. Estos desplazamientos no son un hecho aislado, durante todo el siglo XIX la provincia de Almería expulsó población (Gómez, 1995). Las playas argelinas fueron destino estacional de muchos pescadores del levante andaluz (Compán, 1989: 227). Las migraciones de almerienses a Málaga, Cádiz y Huelva, debieron ser continuas a lo largo del XIX. Pero es a finales de esa centuria, empujados por el crecimiento demográfico y la crisis económica (Sánchez, 1999:48) cuando esos desplazamientos se aceleran y, en algunos casos, se convierten en permanentes. Será en la provincia de Huelva donde se concentre el mayor número de almerienses. Se asentarán en Punta del Moral y Punta del Caimán, playas situadas entre Ayamonte e Isla Cristina. Allí se mezclarán marineros portugueses, malagueños y gentes del levante, especialmente de Adra, Carbonera y Garrucha, dando lugar al surgimiento del poblado de pescadores de Punta del Moral. También serán malagueños (principalmente de Fuengirola y Los Boliches) y, sobre todo, almerienses (de Cabo de Gata, Carboneras o Roquetas) los trabajadores más representativos, cuantitativamente, en las almadrabas enclavadas en el litoral gaditano, hasta prácticamente la década de los setenta del siglo pasado, cuando el Consorcio Nacional Almadrabero decida cerrar buena parte de las almadrabas onubenses (Zaragoza, 2011). Desde entonces, estos puestos en los enclaves gaditanos los acapararán los almadraberos procedentes del poniente andaluz, cuya presencia se mantiene hasta la actualidad.

Los movimientos poblacionales desde el Mediterráneo al Golfo de Cádiz no se agotan aquí. En la década de los veinte del siglo pasado se iniciará una corriente migratoria desde aguas alicantinas (Calpe, Denia, Villajoyosa, Torrevieja, Benidorm...) hacia el Atlántico andaluz. Alcanzará su momento de auge después de la Guerra Civil y se prolongará hasta los años cincuenta (Ferrer, 1991). Estas migraciones tendrán un carácter distinto a las almerienses ya que, además de los marineros, se trasladan también los armadores con sus embarcaciones. Málaga, Algeciras, El Puerto, Sanlúcar, Conil, Punta Umbría o Huelva son sus principales destinos. Estos desplazamientos son consecuencia de la motorización de la flota pesquera mediterránea que la dotará de una mayor capacidad de movilidad y la posibilidad de buscar caladeros más alejados. La cercanía de las aguas africanas hace que tomen los puertos andaluces como base. No se trata de un hecho nuevo, Andalucía viene siendo centro para la pesca en África desde la Edad Media. En 1940, la colonia de alicantinos en El Puerto de Santa María era de 700 personas, un 30\% 
de la población marinera local (ibid.368). Su participación en la fundación del Pósito Marítimo y de Pescadores del Puerto de Santa María en 1934, evidencia la influencia que este colectivo tuvo en el sector pesquero local (ibid.367). Si durante un tiempo los alicantinos constituyeron una colonia cerrada, con el tiempo su presencia se irá diluyendo.

En la década de los cuarenta del siglo XX veremos cómo comienzan a llegar a los puertos de Cádiz, Algeciras y Huelva embarcaciones procedentes del litoral gallego. Las mejores condiciones ambientales en las aguas del sur, la situación política favorable para pescar en África, con el establecimiento del Protectorado de Marruecos, y la inseguridad de las aguas europeas durante la Segunda Guerra Mundial serán algunas de las causas que impulsan a los pescadores gallegos a navegar hasta el Golfo de Cádiz (Broullón, 2010). Ya en el primer cuarto del siglo XX se registran algunas embarcaciones de Galicia en aguas andaluzas pero esa presencia era temporal. Los barcos pescaban en África y, una vez acabada la campaña, regresaban a los puertos gallegos. A partir de los cuarenta, muchos armadores cambiarán de estrategia. Para ahorrar costos establecerán sus bases definitivamente en Cádiz y Huelva. Este cambio modificará el tipo de emigración. Si en un principio era exclusivamente masculina, desde entonces adquirirá un carácter familiar. En el padrón de Cádiz de 1940 aparecen registrados 1945 personas de origen gallego. En 1955 eran 2000 (Broullón, 2010:39).

La década de los sesenta del siglo XX marcará un cambio de signo en las migraciones pesqueras en Andalucía. Si hasta entonces las aguas andaluzas habían sido un foco de atracción para pescadores de diversas zonas, ahora se abrirá un ciclo en el que serán los marineros andaluces los que salgan a pescar a otras aguas. La Ley de Renovación y Protección de la flota pesquera de 1961 supondrá un punto de inflexión en la pesca andaluza. A partir de 1968, en el puerto de Huelva surgirá una flota de congeladores de gran altura (Fourneau, 1988:125) y, como en siglos anteriores, los marineros andaluces faenarán en aguas africanas. Pero ahora los desplazamientos son aún más al sur, en torno al Golfo de Guinea, Angola y África del Sur. En estas embarcaciones se mezclarán marineros africanos y andaluces. El crecimiento de esta modalidad pesquera se prolongará hasta 1973. La pérdida de los caladeros situados en las aguas territoriales, el alza de los precios del petróleo y las movilizaciones laborales conducirán a una profunda crisis. A pesar del espectacular crecimiento de la pesca de gran altura, el sector no absorbió ni siquiera la población marinera de la provincia. El destino de muchos marineros será la emigración.

Esa misma ley de 1961 propiciará la creación de una potente flota de altura en los puertos vascos (bacaladeros, congeladores). A mediados de los sesenta comenzará la diáspora de pescadores andaluces hacia esa zona. Lekeitio, Ondarroa, Motrico, Bermeo y Pasajes serán sus principales destinos. Mientras que los pescadores vascos se centrarán en la pesca de bajura, los emigrantes andaluces y gallegos tripularán estas embarcaciones de altura. Este ciclo se cerrará en 1977 en el que se produce el retorno de muchos de estos 
marineros. Ese año, la entonces Comunidad Económica Europea aplica la normativa internacional de las Zonas Económicas Exclusivas (ZEE) hasta las 200 millas, lo que supone un importante revés a las embarcaciones vascas.

Si hasta la década de los sesenta fueron más frecuentes las migraciones desde el Mediterráneo hasta el Atlántico, desde entonces se ha invertido la dirección de estos flujos. La fuerte crisis del sector pesquero del atlántico andaluz como consecuencia de las restricciones para la pesca en Marruecos con la aplicación de las ZEE en el contexto del nuevo orden internacional marítimo (Suarez de Vivero, 1985) ha impulsado a numerosos marineros que faenaban en los caladeros marroquíes a desplazarse con sus familias a otros puertos, especialmente del Mediterráneo y, en menor medida, canarios. Un ejemplo paradigmático es el caso de la emigración de los marineros de la flota de cerco de Barbate a puertos donde se desarrolla este tipo de pesca: Palamós, Tarragona, Barcelona y, especialmente, al puerto del Grao de Castellón (Florido, 2002) ${ }^{8}$. En este último puerto, la presencia de marineros barbateños es muy significativa, constituyendo, junto al resto de marineros andaluces (almerienses, malagueños y, en menor medida, onubenses) casi la mitad (47\%) del total de los marineros de este puerto (Llorca, 2002).

¿Hasta qué punto estos flujos humanos, técnicos y económicos han constituido un factor articulador del litoral andaluz? Entendemos que poner el foco de análisis en la movilidad poblacional que la pesca ha provocado y provoca, nos orienta hacia la idea de la vertebración del litoral andaluz como un factor constante a lo largo de su historia. Estudiar la pesca sin los pescadores nos limitaría en este empeño. Por tanto, preguntarse quiénes son esos marineros y pescadores que esconden las estadísticas, de dónde proceden, qué experiencias colectivas acumulan y/o aplican a las nuevas situaciones medioambientales, tecnológicas y/o sociopolíticas, cómo viven y cuál es la posición social y simbólica que ocupan en los lugares de destino, nos arrojaría luz sobre la existencia de una vertebración social del litoral.

\section{EL LEVANTE EN EL PONIENTE: PESCADORES ALMERIENSE EN LA COSTA DE HUELVA, PUNTA DEL MORAL}

El caso que aquí presentamos nos parece especialmente ilustrativo, no sólo por tratarse de movimientos de marineros de un extremo a otro de Andalucía, desde la costa de Almería hasta la de Huelva, sino, también, porque ha tenido como consecuencia el surgimiento de una comunidad de pescadores, Punta del Moral, que ha pervivido hasta nuestros días y que ha jugado un papel decisivo en el desarrollo de la actividad pesquera de la zona más occidental del litoral de Huelva.

En la actualidad, Punta del Moral es un pequeño núcleo de pescadores convertido en

8. Esta emigración no ha dejado de producirse en las últimas décadas en el contexto de la Política Pesquera Común que promueve la paulatina reducción de la flota. 
centro turístico, perteneciente al municipio de Ayamonte. Se encuentra ubicado al sureste de su término municipal, en la desembocadura del Río Carrera, frente a la localidad de Isla Cristina. Es bien conocido en Ayamonte el origen foráneo de los punteros y hasta hace relativamente poco se consideraba una población claramente diferenciada ${ }^{9}$. Por su procedencia, sus habitantes recibían el nombre de levantiscos.

Los orígenes de Punta del Moral hay que buscarlos en los movimientos poblacionales que tienen lugar en el tercer cuarto del siglo XIX en el litoral andaluz. La superpoblación y la crisis económica, tanto minera como agraria ${ }^{10}$, que vivió Almería en esa época empujaron a muchos almerienses del litoral a emigrar hacia el Golfo de Cádiz que, como apuntamos en el apartado anterior, constituía un hervidero pesquero industrial. No se trata de un fenómeno nuevo ya que estos pescadores habitualmente solían acudir a trabajar en las almadrabas atlánticas. Pero ahora esta emigración adquiere características distintas. No sólo se emplearán en la captura del atún sino, también, en las embarcaciones sardineras, denominadas galeones, que habían empezado a proliferar en Ayamonte e Isla Cristina en el último cuarto del XIX para abastecer las nacientes industrias conserveras (Cáceres, 2002). Otra diferencia importante con migraciones anteriores es que muchos de estos emigrantes no regresarán a su tierra de origen.

En tierras onubenses, estos pescadores se instalaron en puntos estratégicos para la actividad pesquera. En Isla Cristina, a las afuera del pueblo, junto a la desembocadura del Río Carrera en un paraje denominado Punta del Caimán formaron un pequeño poblado. Al otro lado de la ría, dentro del término de Ayamonte, en el lugar conocido como Punta del Moral, encontramos otro contingente. Un grupo más reducido se asentó en la Barriada de Canela, un pequeño barrio de pescadores de Ayamonte donde, al calor del desarrollo pesquero, se había levantado la infraestructura terrestre necesaria para los galeones sardineros.

Es difícil precisar cuándo comenzaron a llegar los levantinos a estos puntos ya que las playas de Huelva han sido, al menos desde la Edad Moderna, destino estacional de pescadores, tanto del Mediterráneo como de la costa portuguesa. Los padrones municipales de Ayamonte registran los primeros almerienses asentados en Punta del

9. A pesar de que es conocida la procedencia de la población de Punta del Moral, en Ayamonte se ignoran las causas que impulsaron a estos pescadores a salir del Almería; incluso los actuales punteños las desconocen. Recientemente hemos podido comprobar este mismo desconocimiento en Carboneras, localidad de donde procede una parte del contingente de pescadores que fundó este núcleo.

10. La población litoral de Almería combinaba la actividad pesquera con la carga de mineral y uva. El desarrollo del ferrocarril favorecerá a los puertos de Almería y Águilas en detrimento del resto de las localidades costeras. A finales del XIX se producirá un descenso de la actividad minera y la filoxera afectará considerablemente al cultivo de la vid. 
Moral a fines del siglo XIX ${ }^{11}$. A pesar del paulatino asentamiento de esta población pescadora, la mayoría de estas familias regresaban a sus lugares de origen una vez finalizada la campaña pesquera. Este constante trasiego se detendrá durante la Guerra Civil, momento en que las familias que se asientan de manera permanente se incrementa exponencialmente. Como hemos podido recoger en los testimonios de personas que vivieron este periodo, en el cambio de estrategia influyó el hecho de que Huelva y Almería durante la contienda quedaron situados en bandos opuestos. A través de los padrones municipales conocemos la procedencia de esos pescadores, entre los que encontramos también marineros malagueños y portugueses. La mayoría de los almerienses eran originarios de Carboneras, pero también los había de Cabo de Gata, Níjar o Garrucha. Llama la atención que a pesar de que proceden de localidades distintas, los apellidos de muchos de los almerienses coinciden, lo que puede indicar la importancia de las redes familiares en estas migraciones.

La evolución sufrida por Punta del Moral y Punta del Caimán fue muy diferente (para esta pedanía cf. López, 2008) ${ }^{12}$. La proximidad al núcleo urbano hizo que en poco tiempo los pescadores de Punta del Caimán quedaran integrados en Isla Cristina y la población almeriense se diluyera. En cambio, Punta del Moral, aislada y alejada más de cinco kilómetros de la cabecera municipal ha continuado manteniendo su identidad levantina hasta ahora.

En sus orígenes, Punta del Moral se encontraba dividida en dos enclaves de pescadores diferenciados. Hasta finales de los cincuenta del siglo pasado se distinguía la denominada Punta de Adentro, más alejada del mar, y una zona cercana a la playa, que se conocía como Punta de Afuera. Entre ambas un territorio despoblado. Mientras que Punta de Adentro estaba habitada mayoritariamente por portugueses y población proveniente de

11. En el padrón de Ayamonte de 1878 aparecen sólo dos marineros de Adra, junto a otros pescadores de puertos mediterráneos (malagueños y alicantinos). Por tanto, cabe deducir que en estos años las emigraciones de los marineros procedentes del levante andaluz están todavía sometidas a la estacionalidad de las actividades almadraberas. Sin embargo, a través del Censo de 1910 comprobamos que el número de familias censadas procedentes de Almería asciende a 62. El otro contingente más significativo cuantitativa y cualitativamente que aparece censado en 1910 lo constituían los portugueses, con un total de 53 vecinos. Verificando este proceso de asentamiento, observamos que el padrón de 1924 ya registra más de 150 familias almerienses.

12. En Punta del Caimán, los padrones municipales no registran almerienses hasta 1916. Ese año, de los 274 habitantes del poblado, nueve proceden de Almería. En cambio, por documentos anteriores conocemos la presencia, al menos desde 1884, de pescadores de Torrevieja, Motril, Málaga, Fuengirola y Cádiz. En el padrón de 1940 eran ya 56 los nacidos en tierras almeriense, la mayoría, al igual que en Punta del Moral, de Carboneras. 
Ayamonte, Isla Cristina y pueblos de alrededor, los de Punta de Afuera eran casi todos emigrantes de la costa oriental de Andalucía. Parece que en un principio existió cierta reticencia de los pobladores más antiguos hacia los levantinos, que al provenir de las mismas localidades y de las mismas familias establecían lazos muy estrechos entre ellos (Valcuende, 2000:32).

Los marineros se concentraban básicamente en cabañas situadas en Punta de Afuera, un área inundable que no disponía de agua potable, mientras que los mandos de las embarcaciones vivían en algunas casas y almacenes ubicados en Punta de Afuera. Durante un tiempo la rivalidad entre las dos zonas fue bastante grande pero, poco a poco, se irá diluyendo al trasladarse la población de la Punta de Afuera hasta la Punta de Adentro. Esa división tenía una plasmación simbólica en las dos festividades que se celebraban, San Antonio, patrón de Carboneras, organizado por los almerienses, y la Virgen del Carmen, ligada a las familias de la zona.

Prácticamente aislados, sin ningún tipo de infraestructura urbana, las condiciones de vida de este poblado durante décadas fueron muy duras. De "terribles guaridas" calificará el periodista Luis Bello las viviendas de Punta del Moral y Punta del Caimán durante su visita a la zona en 1928 (Bello, 2007: 284). Hasta hace un par de décadas en que irrumpió el turismo, la mar fue la única fuente de recursos de los punteros. La pesca de la sardina se prolongaba de marzo a octubre, y la del atún desde junio a septiembre, por eso, cuando el poblado se hizo permanente fue necesario buscar actividades económicas que permitieran la subsistencia todo el año. Igual que los marineros de Ayamonte e Isla Cristina durante el otoño y el invierno, los de Punta del Moral debían echar mano a las modalidades de pesca artesanal que les permitieran obtener algunas capturas, dedicándose al marisqueo o al trasmallo. La situación de Punta del Moral, en plena línea de costa, favorecía el desarrollo de la actividad pesquera con relación a la cabecera municipal. Mientras que en Ayamonte el marisqueo sólo era posible en el río o requería desplazarse hasta la playa, en Punta, cualquiera podía coger almejas y coquinas, incluso mujeres y niños se dedicaban a estos menesteres. Igualmente, la proximidad de la marisma permitía la práctica de tapaesteros y lavadas. La pesca de bajura también se veía favorecía por tener acceso directo a la mar, al contrario que las embarcaciones ayamontinas que siempre tuvieron el escollo, por ser un puerto interior, de una gran barra de arena que complicaba la salida y entrada de las naves. La emigración temporal también formaba parte de la estrategia económica de los punteros. La especialización en la pesca del atún les llevó, cuando faltaba trabajo en el Golfo de Cádiz, a trasladarse a las almadrabas de Italia y el norte de África, sobre todo, a Larache donde diversos industriales isleños armaban almadrabas y tenían fábricas de conservas. Frecuentemente iban acompañados por sus esposas que se empleaban como obreras de esas industrias conserveras.

La evolución de la actividad pesquera en Ayamonte y Punta del Moral ha sido muy 
diferente. Como veíamos, la ubicación geográfica ha jugado un papel decisivo en este sentido, al no tener que salvar los punteros el escollo de la barra para acceder a la mar. También ha influido la situación de pobreza y marginalidad en la que vivían los pescadores de Punta del Moral, que les obligó al desarrollo de una serie de estrategias de supervivencia. Pero creemos que un elemento clave que no convendría infravalorarse para entender esta evolución divergente es la procedencia de sus habitantes. El asentamiento definitivo en el litoral onubense no supuso la ruptura total de relaciones con Almería. Aunque con el tiempo se han ido debilitando aún siguen existiendo lazos familiares. Este hecho ha permitido a estos pescadores conocer tanto la realidad pesquera de Huelva como la de su tierra de origen, dotándolos de muchos más recursos a la hora de explotar el medio pesquero, utilizando de una serie de conocimientos técnicos provenientes del Mediterráneo e implementando estrategias económicas experimentadas en sus lugares de origen. Sería de gran interés el desarrollo de investigaciones que incidieran en este aspecto, en conocer cómo ha influido en la actividad pesquera la trasmisión de tecnología y culturas del trabajo de unas zonas a otras del litoral andaluz.

A su llegada, capturaban las mismas especies que los ayamontinos e isleños pero, además, se sirvieron de otras que en Huelva no se utilizaban. En los años cuarenta cuando la pesca de sardinas con grandes barcos entró en una fase de crisis, los punteros afrontaron la situación introduciendo del Mediterráneo los denominados sardinales, un arte de deriva para la pesca de la sardina mediante enmalle, consistente en una pequeña red rectangular que se cala con barco a vela de escasas dimensiones. Tanto las redes como algunas de las pequeñas barcas que usaban procedían de la costa mediterránea. La estrategia económica de los punteros a partir de esa época consistirá en combinar los sardinales con otras modalidades artesanales que requerían muy poca mano de obra.

En Ayamonte, la flota sardinera se reconvirtió y las grandes embarcaciones fueron sustituidas por pequeños barcos a motor, traíñas, con más movilidad. A la vez, se creará una flota dedicada a la pesca de arrastre, son las denominadas parejas. Estos barcos necesitaban mucha menos mano de obra y, a finales de la década de los sesenta, con la crisis del sector conservero, comenzará una emigración masiva de marineros a los puertos del País Vasco. La flota ayamontina desaparecerá totalmente, en cambio, gracias a la dedicación a la pesca artesanal, basada en los conocimientos técnicos adquiridos en sus lugares de origen y una forma de reclutamiento con base familiar, la actividad pesquera se pudo mantener en Punta del Moral, adaptándose a la nueva coyuntura económica. A partir de los años ochenta comenzará una etapa de modernización y crecimiento. Las pequeñas barcas serán remplazadas por barcos de arrastres que se adquieren gracias a las ayudas comunitarias. Hoy día la flota puntera se compone de un buen número de barcos de gran tonelaje que captura marrajos y gambas en el Golfo de Cádiz. También dispone de una flotilla de pequeñas barcas dedicada a la pesca del pulpo, al trasmallo 
y al palangre. Prueba del desarrollo pesquero experimentado por Punta del Moral fue la salida de sus embarcaciones de las cofradías de pescadores de Ayamonte e Isla y la constitución de una asociación de armadores punteros. También deja ver claramente su potencial pesquero el hecho de que en los últimos años la flota de Punta ha tenido que recurrir a mano de obra proveniente de Ayamonte e Isla Cristina.

En Ayamonte la actividad pesquera siempre tuvo un carácter industrial, desde el siglo XIX los marineros fueron asalariados de los grandes barcos. En cambio, en Punta del Moral se combinaba el trabajo asalariado con la pesca artesanal, con pequeños barcos y aparejos muy simples. Era frecuente llevar en la misma barca diferentes artes y calar uno u otro, o varios, dependiendo de las circunstancias. En las embarcaciones solían ir de manera casi exclusiva miembros de una misma familia. De ahí la importancia que ha tenido, hasta hace muy poco, el tener un elevado número de hijos varones. Ha sido la garantía de disponer de mano de obra suficiente. Este hecho, y no solo la situación económica, explica que fuesen muy pocos los niños que pasaban de la educación primaria. Los profesores se quejaban de que eran los padres los que alentaban el abandono de la escuela a muy corta edad para dedicarse a la pesca (Valcuende, 1998:194). Una frase típica de los niños refleja esta estrategia: "cuando tenga la edad me saco el folio y me embarco". Hasta hace muy pocos años no llegaron algunos niños a la universidad, pero, incluso los jóvenes que accedían a una educación superior, debían colaborar en la pesca durante los periodos vacacionales. En todos estos barcos, el dueño ejercía, a la vez, de patrón. Incluso cuando los barcos fueron mayores, los armadores continuaron embarcándose, algo impensable para un propietario ayamontino.

Dado el pequeño tamaño de Punta del Moral, los lazos familiares entre sus habitantes han sido muy estrechos. No solamente se han mantenido el parentesco en una primera y una segunda generación sino, también, en tercer y cuarto grado. Es frecuente que al hablar los punteros entre sí, utilicen el apelativo "primo". Lo que lleva a los ayamontinos a afirmar que en Punta del Moral todos son familia. Punta del Moral se presenta de cara al exterior, frente a Ayamonte, como una gran familia donde todos se llevan bien. Estas relaciones de parentesco han sido aprovechadas para el reclutamiento de mano de obra, así en una embarcación es frecuente que vayan padre, hermanos, tíos y "primos". Mientras que en Ayamonte uno de los problemas a los que debió enfrentarse el sector pesquero, a partir de los años sesenta, fue a la subida del coste de la mano de obra, en Punta la contratación de familiares ha constituido la fórmula más extendida para disponer de mano de obra sin que exista conflictividad laboral. Los marineros trabajaban por una parte menor y sin plantear demasiadas reivindicaciones.

El aislamiento de la cabecera municipal ha sido uno de los hechos que más ha marcado la vida de Punta del Moral. El abandono por parte de Ayamonte de este enclave era evidente, las calles estaban hasta hace muy poco sin asfaltar y hasta los años cincuenta no 
se construyeron casas para los marineros. Era una población totalmente desprovista de un equipamiento mínimo, sin agua, luz o teléfono. A finales de los sesenta comienza una progresiva y lenta dotación de servicios, que no culminará hasta finales de los setenta. En esa década se construye la carretera que une Punta del Moral y Ayamonte. Hasta hace muy poco carecía de todo tipo de infraestructura pesquera a pesar de contar con una importante flota. La lonja y la fábrica de hielo siguen estando en el puerto de Ayamonte. El aislamiento ha permitido el mantenimiento de una serie de rasgos distintivos con respecto a los ayamontinos. El acento de los punteros es diferente, con una marcada jota almeriense, con los típicos diminutivos acabados en ico y con una prominente entonación levantina. Pero, a la vez, con el ceceo característico del litoral onubense. Su gastronomía también mezcla el levante y el poniente andaluz. Algunas de sus costumbres han sido utilizadas por ayamontinos como elementos ridiculizadores, pero no tanto por su origen, como por ser consideradas fruto de la barbarie en que vivían los punteros. Es el caso de los denominados encierros, matrimonios por fuga. Se trata de una estrategia matrimonial de clase que encontramos en diversas zonas de Andalucía y que era muy común entre las clases más desfavorecidas del levante almeriense (Frigolé, 1999). En el contexto onubense esta práctica no se entendía y se interpretaba como un síntoma de primitivismo. En más de una ocasión hemos escuchado decir: "en La Punta la gente ni se casa, se encierra y ya está". Frecuentemente los punteros para evitar escarnios trataban de ocultar esta forma de matrimonio. Lo mismo ocurre con algunas de sus supersticiones. Famoso es en Ayamonte el miedo que existe en Punta del Moral a nombrar la palabra Carboneras, el nombre del pueblo de Almería de donde proceden parte de los habitantes. Se trata de una especie de tabú, símbolo de mal agüero. Para referirse a carboneras solían hacer referencia al pueblecico.

La imagen que los ayamontinos tienen de los punteros es muy parecida a la que tienen de sus vecinos de Isla Cristina que también proceden del Levante, pero no de Andalucía sino de Cataluña. Igualmente, a los isleños se les aplicaba el calificativo de levantiscos.

Este devenir histórico ha provocado un fuerte sentimiento de identidad entre los "punteros" frente al municipio matriz, del que ha habido conatos de peticiones de segregación municipal. Es por ello que en la actualidad se han multiplicado los apoyos municipales hacia esta población, tradicionalmente segregada y estigmatizada a nivel social y espacial. Aparte del valor económico (pesca y turismo), la Punta del Moral representa un gran valor simbólico para el municipio, pues este sigue fundamentando su identificación en las actividades pesqueras, inexistentes ya en el municipio matriz. Es por ello que hablar de pesca hoy en Ayamonte es hablar de Punta del Moral ya que la flota pesquera oficialmente ayamontina refiere a las embarcaciones de esta población. Si Ayamonte se sigue proyectando como un pueblo marinero es gracias a esos pescadores procedentes de Almería. 


\section{A MODO DE EPÍLOGO}

La invisibilidad que han padecido los pescadores y sus familias en el imaginario colectivo de los andaluces y de sus instituciones públicas hasta prácticamente el presente siglo entronca con la escasa visibilidad que han experimentado en sus respectivos municipios. Muchos barrios o poblados de pescadores han desenvuelto su cotidianidad de forma apartada (en la mar y en la tierra) siendo objeto de percepciones locales que los concebían tradicionalmente con una existencia "naturalizada" frente al rasgo civilizatorio que estas entidades han pretendido destacar históricamente en sus construcciones identitarias. Muchos de estos municipios litorales han construido su imagen colectiva en torno a otras actividades, dando su espalda al $\operatorname{mar}^{13}$. En aquellas poblaciones en que su referente colectivo se ha construido en torno a la "maritimidad", en muchas ocasiones han utilizado el mar como depositario de grandes gestas militares o comerciales. Por su parte, poblaciones como Ayamonte, Isla Cristina o Barbate donde el "orgullo" local se ha nutrido históricamente de las actividades pesqueras, sus elaboraciones se han centrado en el progreso y "modernidad" que ha imprimido la industria pesquera en posición contrastiva con los municipios colindantes, eminentemente agrícolas en su mayoría.

Efectivamente, en el contexto de las sucesivas recapitalizaciones que recibe el sector pesquero desde mediados del siglo XIX, algunas poblaciones litorales andaluzas han construido sus señas de identidad frente a una Andalucía rural, pobre y cerrada, ensimismada. Las modernas fábricas, el trasiego de foráneos al albur del progreso, el mar como elemento de conexión con otros puertos, otras tierras, otras gentes y culturas, la apertura de mentalidades a que da lugar estas experiencias colectivas, la mirada puesta en el futuro frente a las elaboraciones que recalcaban el pasado histórico, fueron algunos de los contenidos con los que se nutrieron las imágenes de estas poblaciones litorales andaluzas. Claro está que estas construcciones se realizaban desde las elites pesqueras que silenciaban las penosas condiciones de trabajo en que tuvieron que desenvolverse los trabajadores/as de las "modernas" fábricas pesqueras y de los barcos; niños y niñas, mujeres y hombres al servicio de un sector cuyo sustento se apoyó en la rentabilización de una fuerza de trabajo que procedía de otras poblaciones litorales o del socavado campo andaluz. Una Andalucía igual de "trágica" por las condiciones de trabajo y de vida que tuvieron que padecer, pero cuya labor se realizaba en un contexto recreado de "prosperidad". Imagen que nos proporcionan buena parte de la documentación de la época, especialmente la prensa escrita. Imagen que en muchas ocasiones, a veces de forma excesivamente acrítica, es reproducida por la historiografía actual.

Un análisis somero de la bibliografía existente nos arroja una visión fragmentaria de la

13. No olvidemos que muchos de estos municipios tienen la cabecera municipal en el interior, alejados varios kilómetros de la costa. 
actividad pesquera en Andalucía. Resulta curioso que a pesar de la prolija producción de historias locales existente en los pueblos y ciudades costeras, apenas haya sido tratada en la mayoría. Muchos datos aparecen de forma tangencial en producciones de temáticas dispares. Buena parte de los trabajos en los que el tema principal es el pesquero se centran en instituciones y políticas pesqueras. Otros se insertan dentro de la Historia Económica, justificando su importancia en términos productivistas: valor de las capturas, número, tipología y descripciones de embarcaciones, artes y técnicas, nivel de capitalización, infraestructuras, mercados y número de marinería empleada. Cuando se justifica en términos productivistas la importancia de la pesca en Andalucía, indefectiblemente se constata la mayor significación de la Andalucía atlántica frente a la Andalucía mediterránea caracterizada por ser eminentemente artesanal. Esta orientación productivista, por tanto, ha propinado que la actividad pesquera en el levante andaluz quede en la mayoría de los casos obviada por irrelevante.

En ocasiones se han realizado trabajos de temática pesquera que se presentan como una aproximación analítica al conjunto de Andalucía, cuandolo que se realiza es un tratamiento dispar de fuentes documentales, básicamente a nivel descriptivo, pero sin un abordaje analítico que caracterice de forma sintética la actividad pesquera andaluza. Otras veces se trata de producciones de metodología metonímica, en que la profundización analítica en algunas poblaciones se extrapola al conjunto andaluz, anulando la variedad, contrastes y complejidad que presenta nuestro litoral. Sin embargo, negamos la importancia del ámbito local en el estudio de la pesca en Andalucía, al contrario, creemos que es uno de los contextos de análisis más apropiado ya que, a diferencia de la actividad agrícola, la pesca se circunscribe a un número relativamente reducido de poblaciones, lo que metodológicamente resulta muy factible de abordar. Pero, sobre todo, es adecuado por la relevancia que tiene a todos los niveles el ámbito local en Andalucía (Escalera, 1999:107; González, 2004:24). Tomar como referencia lo local no debería suponer estudiar las poblaciones pesqueras como entidades aisladas sin conexión con otros ámbitos territoriales.

El productivismo como enfoque analítico también está presente cuando el análisis se focaliza en el conflicto social. Así, cuando se estudian los enfrentamientos originados en torno a la incorporación de tecnología pesquera (embarcaciones, técnicas y artes), con demasiada frecuencia se observa la discrepancia entre los que, usando esquemas excesivamente simplificadores, abogan por los "emprendedores" y "vanguardistas" que fomentan la productividad, frente a los "tradicionalistas" e "inmovilistas" que se aferran al pasado. Esto es lo que ocurre cuando se analiza el papel jugado por los "fomentadores" catalanes en la capitalización del sector pesquero andaluz en los albores del Nuevo Régimen al introducir innovaciones tecnológicas y configurar nuevos circuitos mercantiles. El protagonismo otorgado a estos comerciantes del levante desde la historiografía catalana 
en ocasiones es asumido de forma casi mecánica por la historiografía andaluza. Este colonialismo intelectual se incardina con el histórico, ya que hablar de expansión pesquera es hablar de colonialismo económico. La intensificación productiva vivida por el sector pesquero andaluz de la mano de los fomentadores catalanes tuvo dos consecuencias inexorables: por un lado, la proletarización de los pescadores con el consecuente desmantelamiento del sector que provoca la miseria y la pérdida de la diversidad de técnicas, artes y conocimiento pesquero (sobre las condiciones de vida de los pescadores cf. Santamaría, 1923; sobre la progresiva reducción de las retribuciones de la marinería cf. García del Hoyo, 2006). Por otra parte, este proceso de intensificación productiva produjo la esquilmación de los caladeros andaluces que tuvo como consecuencia directa una crisis pesquera en la costa andaluza de la que tardará más de medio siglo en recuperarse. Ambos factores nutrieron las bases argumentativas de la oposición de los pescadores andaluces a lo que consideraron una invasión externa. Este hecho generó una ingente documentación histórica de diferente índole que refleja dos elementos, fuertemente imbricados, fundamentales para el análisis de este proceso. De una parte, la generación de unos discursos de gran modernidad basados en la preservación ecológica de los caladeros y, de otra, la defensa de los intereses de los pescadores andaluces, a través de las apropiaciones simbólicas que realizaban del espacio marítimo frente a los "otros" externos que observaban nuestras costas como lugar idóneo para la obtención de recursos y mano de obra barata en el contexto de la liberalización del sector promovido por las instancias estatales ${ }^{14}$.

Resaltando la necesidad, calidad e importancia de la mayoría de estos trabajos, entendemos que la síntesis a nivel andaluz pasa por considerar la "cuestión social", expresión que indefectiblemente ha estado asociada en la historiografía andaluza con el problema del campesinado y de la tierra. En la mayoría de los estudios pesqueros el pescador se configura como un factor invariable y homogéneo. Opuesto al mismo se sitúa al "fomentador" que progresa, industrializa, se expande, moviliza capitales y crea riqueza. Además esta dualización se territorializa, dentro del esquema que hemos apuntado más arriba, cuyos extremos los constituyen el pescador almeriense frente al fomentador onubense:

\footnotetext{
14. Estas imágenes historiográficas también se mantienen cuando se trata de analizar acontecimientos actuales. Al analizar el trabajo de los marineros andaluces, algunos escritos lo valoran en términos de "descualificación". De este modo, el discurso económico de la "descualificación" como mecanismo estratégico de reducción de las retribuciones laborales es adoptado de forma acrítica. Se hace correlacionar cualificación con formación reglada, desestimando paradójicamente el aporte del conocimiento marinero y pesquero adquirido empíricamente en sus lugares de origen que es, en definitiva, la causa por lo que se enrolan en esos puertos de destino.
} 
“... el pescador almeriense anclado a su tradicional pesca con artes de jábega frente al fomentador de la costa occidental de Huelva, rico potentado que coloniza otras áreas pesqueras y es capaz de desarrollar poderosas industrias de transformación e introducir mejoras técnicas de carácter vanguardista en sus equipos pesqueros" (Ríos, 2006: 927).

Este esquema dual no se analiza desde el enfrentamiento consustancial a sus posiciones encontradas en las relaciones sociales de producción, sino como referentes personalizados de dos modelos de racionalidad económica connotados apriorísticamente como "riqueza y progreso" frente "estancamiento y arcaísmo" donde se priorizan las macromagnitudes en el análisis solapando los efectos que para la fuerza de trabajo ocasiona la intensificación capitalista. Trabajo y trabajadores que son observados como una categoría monolítica que a lo sumo recoge la distinción, aunque la mayor parte de las veces no de forma explícita, entre pescadores artesanales y marineros "asalariados". Queda así eclipsada la diversidad y complejidad que entrañan las múltiples formas diferenciadas de experimentar el trabajo en el sector. Diversidad y complejidad que no solo se sustenta en las posiciones diferenciadas en las relaciones sociales de producción, sino que responde también a las experiencias distintivas que se deriva, por ejemplo, del uso de técnicas y artes diferentes que atraviesa a aquellas. De esta manera, las denominaciones de carácter emic han de ser sustraídas con el objeto de dar cuenta de la riqueza y complejidad que comporta el mundo pesquero en sus formas de elaborar cultura.

Esta realidad se complejiza aún más cuando estamos ante un sector que se ha caracterizado históricamente por su movilidad territorial. Movilidad que no sólo refiere al consustancial desplazamiento en el territorio marítimo y portuario, lo que obliga a compartir tiempos y espacios, no sin conflictos en muchos casos, con marineros de procedencia múltiple, sino también, y sobre todo, a los asentamientos de carácter temporal, estacional o permanente que han originado convivencias entre las familias pescadoras y marineras de procedencia diversa y entre estos y las poblaciones de "acogida" centradas en actividades igualmente dispares.

La perspectiva analítica que aquí proponemos no refiere a los movimientos poblacionales derivados de las actividades pesqueras a lo largo de la historia como un objeto de estudio más sino como una propuesta epistemológica. Entendemos que encarar el estudio histórico y actual de la actividad pesquera desde esta perspectiva proporciona herramientas metodológicas suficientes para desmantelar la rigidez de los esquemas excesivamente simplificadores denunciados anteriormente. La denuncia de esta triple invisibilidad (de las actividades pesqueras en la historia de Andalucía, de la complejidad sociocultural que comportan y de los movimientos poblacionales a que dan lugar) implicaría cambios en la forma de historiar Andalucía, en el contexto de la transición epistemológica de la historia en Andalucía a la historia de Andalucía que nos propone 
Lacomba (2000). Todavía algunos planteamientos pretenden justificar la importancia de la historia pesquera andaluza en el marco del Estado Español, una historia que también se valora en términos de representatividad cuantitativa. De esta manera, en muchas ocasiones la historia de la pesca en Andalucía se desfigura entre lo local o comarcal y la contextualización estatal o supraestatal.

En el último medio siglo, a la par que se ha ido fomentando una visión de nuestro litoral como un espacio de ocio, de descanso y/o de diversión para andaluces y foráneos, se ha producido una destrucción paulatina del sector pesquero andaluz. Rescatar el devenir histórico de las poblaciones pesqueras andaluzas en su dinamismo y articulación supone, parafraseando a Lledó (1996), sentar las bases para procurar la presencia de una ausencia en la memoria colectiva de los andaluces. 


\section{REFERENCIAS BIBLIOGRÁFICAS}

Alegret, J. L. (2003) "Valoración patrimonial del sector pesquero". Boletín del Instituto Andaluz del Patrimonio Histórico, 44, pp. 34-41.

Athaide Oliveita, F. X. (1908) Monografia do Concenho de Vila Real de Santo Antonio. Oporto: Livraria Figueirinhas.

Bello, Luis (2007) Viaje por las escuelas de Andalucía. Sevilla: Renacimiento.

Broullón Acuña, Esmeralda (2010) Gallegos en Cádiz. Redes sociales y estrategias familiares de las pesquerías gallegas en Cádiz durante el siglo XX. Cádiz: Universidad de Cádiz.

Burgos Madroñero, Manuel y Lacomba, Juan Antonio (1993) "El sector pesquero en Andalucía en la primera mitad el siglo XIX. Una aproximación”. Estudios Regionales, 35, pp. 15-50.

Cáceres Feria, Rafael (2002) Mujeres, fábricas y charangas: el trabajo femenino en el sector conservero de Ayamonte (Huelva). Huelva: Diputación Provincial de Huelva. Consejería de Educación de la Junta de Andalucía.

Cáceres Feria, Rafael (2007) “Fábricas o molinos?: reflexión sobre la destrucción del patrimonio pesquero-conservero de la localidad onubense de Ayamonte". En Ana María Aranda Bernal (Coord.), Arquitectura vernácula en el mundo ibérico: actas del congreso internacional sobre arquitectura vernácula. Sevilla: Universidad Pablo de Olavide, pp. 429-434.

Compán Vázquez, Diego (1989) "La pesca marítima en Andalucía”. En Cano García (Dir.), Geografía de Andalucía, V, pp. 201-279.

Corbacho Gandullo, M. Ángeles (2006) "Patrimonio pesquero y territorio marítimo: pesca litoral y almadrabas en Barbate", Anuario Etnológico de Andalucía (2003-2005). Sevilla: Consejería de Cultura, Junta de Andalucía, pp.43-64.

Escalera Reyes, F. J. (1999) “Territorios, límites, fronteras: construcción social del espacio e identificaciones colectivas". En Pujadas Muñoz et al. (Eds.), Globalización, fronteras culturales y políticas y ciudadanía. VIII Congreso de Antropología. Santiago de Compostela: FAAEE y Asociación Galega de Antropología, pp. 99-108.

Ferrer Andrade, José (1991) “La gente de Levante y su relación con la pesca en el Puerto de Santa María a mediados del siglo XX”. Revista de Historia del Puerto, 7, pp. 363-372.

Florido del Corral, David (2003) "Hacia una patrimonialización de la cultura de la pesca en Andalucía”. Boletín del Instituto Andaluz de Patrimonio Histórico, 44, pp. 30-36.

Florido del Corral, David (2004) La pesca en Andalucía. Factores globales y locales de un proceso de crisis. Sevilla: Fundación José Manuel Lara. 
Fourneau, Francis (1983) La provincia de Huelva y los problemas de desarrollo regional. Huelva: Diputación Provincial de Huelva.

Frigolé, Joan (1999) Llevarse a la novia. Estudio comparativo de matrimonios consuetudinarios en Murcia y Andalucía, Barcelona: Bellaterra.

Gómez Díaz, Donato (1995) Las migraciones almerienses. Una historia económica hasta 1910. Almería: Instituto de Estudios Almerienses.

González Alcantud, J.A. (2004) Deseo y negación de Andalucía. Lo local y la contraposición oriente / occidente en la realidad andaluza, Granada: Universidad de Granada.

Gonzálvez Escobar, J. L. (1988) Los orígenes de Isla Cristina. El Impulso pesquero. Isla Cristina: Ayuntamiento de Isla Cristina.

Jou Andreu, David (1995) Catalanes en Isla Cristina. Aportación al estudio de los primeros pobladores de la antigua Isla de la Higuerita. Isla Cristina: Ayuntamiento de Isla Cristina.

Lacomba, J. Antonio (2000) "Las etapas de la reconstrucción historiográfica de la historia de Andalucía. Una aproximación”. Revista de Estudios Regionales, 56, pp. 15-48.

Llorca Sellés, Manuel (2002) “Inmigración en la pesca en el puerto del Grao de Castellón", Papers: Revista de Sociología, 66, pp. 187-197.

López Márquez, Vicente (2008) “Levantiscos en la Punta del Caimán”, Revista de fiestas de Ntra. Señora del Mar, Isla Cristina: AVV El Caimán.

López Martínez, Antonio Luis (2004) "La presencia portuguesa en el litoral occidental onubense, 1870-1936”. Huelva en su Historia, 11, pp. 187-202.

Martínez Shaw, Carlos (1978) "Las relaciones económicas entre Cataluña y la Baja Andalucía en el siglo XVIII". En Actas del I Congreso de Historia de Andalucía. Córdoba: Publicaciones del Monte de Piedad y Caja de Ahorro de Córdoba, pp.347-356.

Miravent y Soler, José (1982) [1824] Memoria sobre la fundación y progresos de la Real Isla de la Higuerita. Madrid: Diputación Provincial de Huelva.

Reder Gadow, Marion (1991) "Conflictos pesqueros catalano-malagueños en la costa de marbellí a mediados del siglo XVIII". Baética. Estudios de Arte, Geografía e Historia (Málaga), 13, pp. 257-279.

Ríos Jiménez, Segundo (2005) "Origen y desarrollo de la industria de conservas de pescado en Andalucía (1879-1936)”. Revista de historia industrial, 29, pp. 55-86

Ríos Jiménez, Segundo (2006) "La pesca en Andalucía (1700-1900): una visión a largo plazo". En Actas I Conferencia Internacional Historia de la Pesca en el ámbito del Estrecho. Puerto de Santa María: Junta de Andalucía, pp. 929-962. 
Rodríguez Santamaría, Benigno (1923) Diccionario de artes de pesca de España y sus posesiones de Ultramar. Madrid: Vda. Rivadeneira.

Rumeu de Armas, Antonio (1956) España en el África Atlántica. Madrid: Instituto de Estudios Africanos (CSIC).

Rumeu de Armas, Antonio (1977) "Las pesquerías españolas en la costa de África (siglos XV y XVI)”. Anuario de Estudios Atlánticos, Vol. 1, 23, pp. 349-372.

Sánchez Picón, Andrés (1999) "La ocupación humana y la explotación económica del litoral almeriense en el pasado (siglos XVI-XX)". En Alfonso Viciana Martínez-Lage, Alfonso Galán Pedregosa (Coord.) Actas de las Jornadas sobre el litoral de Almería: caracterización, ordenación y gestión de un espacio geográfico, pp. 35-51.

Valcuende del Río, José María (1998) Fronteras territorios e identificaciones colectivas. Sevilla: Fundación Blas Infante.

Valcuende del Río, José María (2000) Érase una vez una isla: recuperación histórica y tradición oral en Canela y Punta del Moral. Ayamonte: Ayuntamiento de Ayamonte. 